ON

\title{
FATTY DEGENERATION OF THE
}

\section{ARTERIES,}

\section{WI'TH A NOTE ON SOME OTHER FATTY DEGENERATIONS.}

By GEORGE GULLIVER, Esq., F.R.S.

Communicated by THOMAS HODGKIN, M.D.

READ FEBRUARY 28TH, 1843.

IT has long been known that the arteries are very liable to a disease in which a soft matter of diverse consistency, and usually of a brown, yellowish, or white colour, forms between the internal and middle coats; that this matter, though it has been variously denominated, has often received the epithets atheromatous and steatomatous; that it is sometimes a forerunner of partial thinning and destruction of the internal membrane, a frequent concomitant of thickening and corrugation of this tunic, and of ossification of the vessels. And it is as well known that their inner surface is extremely subject to small opaque white or buff-coloured spots, either isolated, grouped together in irregular patches, arranged in streaks, or so diffused as to present 
merely a clouded or speckled appearance. These spots are seated in the internal membrane, occasionally confined to the epithelium, often occupying the whole thickness of the coat, and extending thence to the middle one, in which stage of the disease the matter first mentioned will generally be found in more or less quantity between the two coats.

But although the frequency of these diseased conditions has made them familiar to the pathologist, and their connection with the cause of aneurism, and with the obstruction and obliteration of arteries, must have occurred to almost every one who has investigated the diseases of the blood vessels, I am not aware that the morbid products in question have yet been made the subject of precise inquiry.

In the matter between the inner and middle coats, the following constituents may be seen with the aid of the microscope, namely :-transparent crystalline plates of a pearly lustre; oily globules of variable magnitude, the largest of which are free, while the smaller spherules are often aggregated together in the form of round, oval, or shapeless corpuscles; small earthy concretions; and a multitude of very minute particles, frequently forming a kind of granular ground for the other objects. When the matter is thick, they will be all best seen after diluting it with water or weak acetic acid. Sometimes the small oily globules form a larger corpuscle by mere aggregation; occasionally they adhere to an albuminous flake; while in the large rounded or oval corpuscles, the little oily particles are usually. 
connected together by a very fine granular precipitate. The appearances just described are represented in the figures 1 and 2.

The fatty matter is often sufficiently abundant to give a greasy stain to paper when dried on it by heat.

The crystals are of cholesterine, as I learn from Dr. Davy, who kindly undertook the examination of different specimens of them which I sent to him for the purpose. Besides the cholesterine, he found that the hot alcoholic solution deposited on cooling a few needle-crystals, which had the properties of cholesteric acid. He also detected in the matter a notable quantity of oleine, with a smaller proportion of margarine, a little albumen, and earth of bones.

I have examined a great number of arteries affected with the disease, and never failed to detect oily globules and an abundance of cholesterine in the matter. Pursuing the instructions of Dr. Davy, I have also repeatedly dried it, as well as the middle coat of the vessel, extracted the fatty materials by boiling alcohol, observed the crystals of cholesterine and some margarine deposited as the solution cooled, and obtained the oleine by evaporating the spirit.

There is almost always atrophy and discoloration of those parts of the middle coat of the artery which happen to be near to the accumulated fatty matter ; and more or less thinning and weakness of this coat appear to be often, if not generally, asso- 
ciated with thickening and corrugation of the internal membrane. On these points Dr. Davy has made similar observations.*

In the spots of the inner membrane, the bright fatty globules are very characteristic, and often plentiful enough to give a greasy stain to paper when dried on it by heat. Their most common arrangement is shown in figures 3 and 4 . Crystals of cholesterine are frequently seen in the spots, though not so commonly as in the more abundant deposit between the internal and middle coats; and the speckled inner tunic generally yields a little cholesterine to hot alcohol.

There is seldom ossification of the arteries, or thickening and puckering of their lining membrane, without the formation of fatty matter between this coat and the middle one, as well as in the substance of both of them. The matter may be so scanty as only to be found after a careful search ; but even in this case, in any places where the middle coat has become thinned or discoloured, or the connection between it and the lining membrane loosened, and a little of the soft opaque matter can be scraped off for examination, the cholesterine and oily particles may be detected with the aid of the microscope; and so it is also with even the smallest quantity of the opaque liquid or pulpy matter which may be found in contact with the bony plates.

* Researches, Physiological and Anatomical, Lond. 1839, vol.i. p. $372 \& 436$. 
In fact, ossified blood vessels, especially when there is any pulpy matter in their tunics, are generally in a state of fatty degeneration. In some portions of aorta which Dr. Davy did me the favour to examine, he found the fatty substances in the bony scales of the inner coat and in both layers of the middle coat. By means of hot alcohol, I have repeatedly extracted cholesterine and oleine from all these parts separately, and from various arteries; and in one instance from the outer sheath of the aorta.

The preceding observations appear to give the following results :-

1. The white or buff-coloured opaque spots of the inner membrane of the arteries are of a fatty nature.

2. The soft matter, which has been generally called atheroma, and which often collects between the inner and middle coats, is also fatty.

3 . The fatty matter is frequently found in the substance of both these coats.

4. A fatty degeneration of the tunics of the arteries is generally connected with that state of them which is the most frequent cause of aneurism, as well as of their obstruction, occlusion, or wasting, in aged people.

5. The matter usually contains cholesterine and oleine, and often some margarine.

6. The tunics of ossified arteries, as well as the bony plates, are often pervaded by the fatty substances just mentioned. 
The fatty specks of the lining membrane are sometimes seen before the age of puberty, and the extension of the fatty disease to the middle coat, and the accumulation of the matter between these tunics, may be often observed before forty. It is about this time of life, and subsequently, that the fatty disease of the tunics is probably the most common cause of those spontaneous ruptures of arteries which so frequently produce sudden death. The decay of the arteries, as age advances, has been almost exclusively attributed to the accumulation of phosphate of lime in their tunics. My observations lead me to infer that the formation of fatty matter in the coats is as generally connected with the change.

It might be supposed that a fatty degeneration of the arteries has been generally recognised, as the epithet steatomatous has been so often applied to them by pathological writers. I cannot find, however, that it has been at all used in strict accordance with its etymological import ; and some of the best observers do not consider the morbid production in question as fatty.* It has been regarded as imperfectly organized fibrine ; $\dagger$ and a French author, $\ddagger$ after expressing his opinion that there is not much

* Craigie, General and Pathological Anatomy, Edinb. 1828, p. 97. Otto, Pathological Anatomy, translated by South, Lond. 1831, p. 331 and 332.

$\uparrow$ Hope on the Diseases of the Heart and great Vessels, Lond. 1839, p. 223.

$\ddagger$ P. H. Berard, Dictionnaire de Médecine, tom. 4. Paris, 1833, p. 133 and 134 . 
difference between the matter called steatomatous and that of atheroma, remarks how desirable it is that we should be informed, from accurate analysis, whether there be any relation between these two morbid productions and tubercle. In short, morbid states of the arteries have been denominated steatomatous, just as vaguely as other diseases have been called caseous, colloid, encephaloid, \&c.

The situation of the disease spoken of as steatomatous is by no means clearly defined; for while it hasgenerally been understood to be contained between the middle and internal coats of the artery, ${ }^{*}$ some authors $\dagger$ have described the affection as seated in the latter coat, or at least as distinct from atheroma; and certain tumours or growths projecting into the cavity of the vessel have received the appellation of steatoma.f

It appears to me, that as the importance of fatty degenerations has never been fully recognised, so their frequency and precise nature has escaped investigation. My observations lead me to infer that certain animal tissues are not more commonly weakened and obstructed by the anormal presence of

* Alex. Monro, Medical Essays and Observations, 4th ed. Edin. 1752, p. 237. Cruveilhier, Dictionnaire de Médecine et de Chirurgie Pratiques, Paris, 1829, tom. 3, p. 397.

† Scarpa, Treatise on Aneurism, translated by Wishart, 2nd ed. Edin. 1819, pp. 88-89. Hodgson, on the Diseases of Arteries and Veins, Lond. 1815, pp. 15-16.

$\ddagger$ Stenzel, De Steatomatibus in Aorta repertis. (Haller, Disp. Morb. 2, 527.) Wittemberg, 1723. 
phosphate of lime than by that of fatty matter. The premises on which this deduction is founded having been given as far as regards the arteries, it remains only to add a few brief remarks on some other parts.

We never hear of fatty degeneration of the testicles, of the kidney and other glands, of the lungs, of the blood, \&c.; yet these affections are rather common in a variety of chronic diseases, especially of old people, and often in connection with great general emaciation.

In wasting of the testicle, and when the functions of that gland are impaired by lingering diseases or old age, the seminal tubes are often more or less obstructed by fatty matter, which occurs in free globules, and in more equal sized and minuter molecules, generally aggregated into comparatively large rounded or irregular masses, nearly opaque, and of a brown or dull yellowish colour. There is reason to believe that the molecules of the semen, which I have elsewhere* described as occurring in healthy animals, are of a fatty nature ; but these molecules do not form the dark granular masses or corpuscles above mentioned. The seminal tubes of mammiferous brutes, which have died in confinement, are sometimes nearly opaque, in consequence of being obstructed with brown granular fatty bodies.

In every variety of consolidation of the lungs, more or less fatty matter will be found. In ruddy 
or red consolidation, the juice chiefly contains pale cells, minute molecules, and a few larger fatty globules. In one case Dr. Davy analysed the pale cells, and concluded that the envelopes contained a large proportion of margarine, and that the molecules were principally composed of oleine. The molecules are probably analogous to the elementary granules of Henle,* which he says are of a fatty nature. How much the molecules differ in size from the larger fatty globules will be seen by a reference to figures 5 and 7 . In brown and leadcoloured consolidation of lung, the fatty matter is generally still more abundant than in the red variety, and occasionally in sufficient quantity to grease paper when dried and heated on it. In this form of pneumonia the chief constituents of the juice are dark granular corpuscles, minute molecules, and a few fatty drops. The corpuscles are very variable in magnitude, but frequently about $\frac{1}{1300}$ th of an inch in diameter; they appear dark when viewed by transmitted light, because they are nearly opaque, for they have a lighter hue when seen by reflected light. They are made up of the molecules, and occasionally include much larger fatty globules. There is reason to believe that they are principally composed of oleine. Dr. Davy examined a part of the lung from which figure 8 was made, and found the fatty matter to be chiefly oleine, with a very small proportion of margarine. He concluded that the molecules were composed of oleine.

* Anatomie Générale, traduit par Jourdan, Paris 1843, p. 161. 
The foregoing observations, and a comparison of the pale cells of red pneumonia with the dark granular corpuscles of brown pneumonia, as depicted in figures 7 and 8 , will show that these two morbid states differ in more respects than in colour. But as the brown and red varieties are apt to be intermingled, so the particles of each will often occur together. The brown consolidation of lung commonly exists in phthisis, and is not at all infrequent independently of tubercular disease.

In gangrene of the lungs, and in inflammation of the black lungs sometimes seen in old persons, fatty globules are generally rather numerous. Some of them are frequently contained in corpuscles like epithelial cells, of which examples are represented in the upper part of figure 5, from ruddy consolidation. Hence it would appear probable that, in some cases, the fatty substance may be secreted or separated from the blood by cells, and not merely derived from it by exudation through the vessels, a circumstance of some interest in relation to the recent doctrine of the ultimate secreting structure.*

The fatty condition of the liver, so well known in pulmonary consumption, has usually been considered as a consequence of impaired respiration. There are some facts, especially those afforded by

* See Henle, Anatomie Générale par Jourdan, p. 211. Goodsir on the Ultimate Secreting Structure, Trans. Roy. Soc. Edin. vol. 15. Carpenter on the Origin and Functions of Cells, p. 23, from Brit. and For. Med. Review, No. 29. 
comparative anatomy, favourable to this view. Yet it has appeared to me, after numerous observations, that the quantity of fatty matter in the liver, as a product of disease, is not regularly increased in proportion to the diminution of the special function of the lungs. I have often found the fatty matter of the liver scarcely exceeding the healthy standard in cases where there was the most extensive tubercular disease of the lungs; and in several other chronic diseases there was an excess of fatty matter in the liver, although the lungs were nearly healthy, quite free from tubercle, and only slightly inflamed. In children cut off by various chronic maladies, but quite free from pulmonary consumption, the liver is not uncommonly surcharged with fatty matter. When this matter is in excess, although plentifully contained in the microscopic cells, as shown by $\mathbf{M r}$. Bowman,* I have generally found it chiefly accumulated in the interlobular fissures and spaces described by Mr. Kiernan, $f$ or at least around the surface of the lobules, where it forms a distinct buff-coloured boundary to each of them. The ruddy-coloured hepatic lobules appear to diminish in size as the paler fatty substance increases. In a few instances it was principally seated in the centre of the lobules.

Seviral months after the foregoing paper was read before the Society, I had an opportunity, for the first

* On the Minute Anatomy of Fatty Degeneration of the Liver : Lancet, 1841-42, vol. i. p. 560.

† Phil. Trans. 1833. 
FATTY DEGENERATION OF THE ARTERIES. 97

time, of consulting the excellent work on Pathological Anatomy by Dr. Hasse,* from which the following passage has been obligingly translated for me by my friend Dr. Willis :- " Bizot often observed in it (atheromatous matter) shining bodies like gold dust, (Gold pulver,) and Cruveilhier saw aggregations which resembled in all respects the plates of cholesterine of many gall-stones. These masses have been examined by Gluget microscopically, and found to consist of aggregations of fat globules."-Hasse, p. 98. I have neither seen M. Gluge's work, nor the observations above referred to of $M$. Cruveilhier.

Explanation of the Figures illustrative of Mr. Gulliver's Paper on Fatty Degeneration of the Arteries, \&s.

\section{PLATE I.}

The objects in the two first figures are magnified about 370 diameters, and about 800 in all the other figures. The relative sizes of the objects are preserved ; and their actual sizes, in the last six figures, may be estimated by the scale, which represents micrometrical spaces of $\frac{1}{4000}$ of an English inch.

Fig. 1.-Thin pulpy matter from between the

* Specielle Pathologische Anatomie. Von Dr. Karl Ewald Hasse. Leipzig, 1841.

† Anatomisch-mikroskopische Untersuchungen, 1839. Heft 1 . s. 130 .

vOL. XXVI. 
inner and middle coats of the aorta. From a man aged 78, who died of pericarditis and hydrothorax.

Fig. 2.-Thicker pulpy matter, from the same situation in the aorta. From a man aged 94, who died of pneumonia. The two preceding figures are fully explained at pp. 86,87 .

Fig. 3.-Left part; fatty globules in an opaque spot of the inner membrane of the aorta, which had longitudinal streaks of such spots opposite to the origins of the intercostal arteries. From a man aged 21, who died of typhus fever. Right part; fatty globules, many of them in streaks, and crystals of cholesterine, in a whitish speck of the inner membrane of the arch of the aorta. From a man aged 32, who died of an injury of the leg.

Fig. 4.-Fatty globules and crystals of cholesterine in whitish opaque specks of the basilar artery. The disease affected both the inner membrane and the circular fibres of the vessel. Many of the minute branches of the cerebral arteries were similarly diseased. From a man aged 60 , who died suddenly of extravasation of blood in the brain.

Fig. 5.-Fatty particles in ruddy consolidation of lung. In the upper part of the figure they are represented in cell-like objects ; in the lower part, free fatty globules or drops are seen. From a woman aged 27, who died of pneumonia succeeding to old pericarditis.

Fig. 6.-Fatty matter in reddish brown consolidation of lung. In the upper and left part, fatty globules in the shapeless fragment of a clot; to the 
FATTY DEGENERATION OF THE ARTERIES. 99

right, a portion of fatty matter not quite globular. In the lower part, three granular corpuscles composed chiefly of minute oily globules. From a boy aged 12 months, who died of pneumonia.

Fig. 7.-Pale cells and minute molecules in red consolidation of lung. The upper half of the figure from a woman aged 42 , the lower half from a woman aged 95, both of whom died of pneumonia.

Fig. 8.-Dark granular corpuscles, a multitude of isolated molecules, and some larger fatty globules, in brown or lead-coloured consolidation of lung. From a woman aged 24, who died of phthisis. The lung contained a great quantity of tubercle; the intervening tissue was much consolidated. 


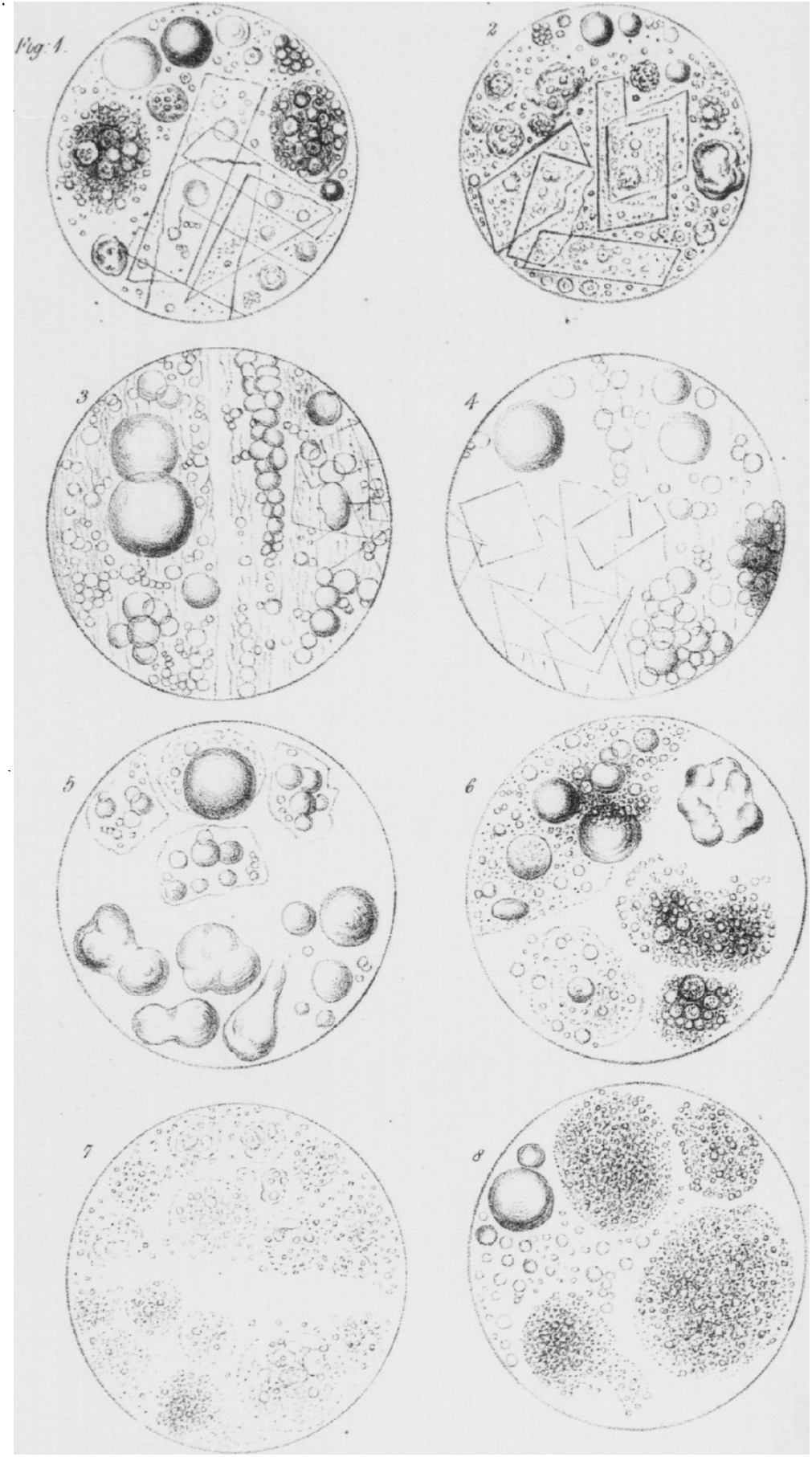

